\title{
Tumor suppressive effect of PARP1 and FOX03A in gastric cancers and its clinical implications
}

\author{
See-Hyoung Park ${ }^{1,2, *}$, Kyu Yun Jang ${ }^{4, *}$, Min Jae Kim ${ }^{1,3, *}$, Sarah Yoon ${ }^{1}$, Yuna Jo ${ }^{1,3}$, \\ So Mee Kwon ${ }^{1,3}$, Kyoung Min Kim ${ }^{4}$, Keun Sang Kwon ${ }^{5}$, Chan Young Kim ${ }^{6}$, Hyun Goo \\ Woo ${ }^{1,3}$ \\ ${ }^{1}$ Department of Physiology, Ajou University School of Medicine, Suwon, Republic of Korea \\ ${ }^{2}$ Program in Nano Science and Technology, Department of Transdisciplinary Studies, Seoul National University Graduate \\ School of Convergence Science and Technology, Suwon, Republic of Korea \\ ${ }^{3}$ Department of Biomedical Sciences, Graduate School, Ajou University, Suwon, Republic of Korea \\ ${ }^{4}$ Department of Pathology, Chonbuk National University Medical School, Research Institute of Clinical Medicine of Chonbuk \\ National University-Biomedical Research Institute of Chonbuk National University Hospital and Research Institute for \\ Endocrine Sciences, Jeonju, Republic of Korea \\ ${ }^{5}$ Department of Preventive Medicine, Chonbuk National University Medical School, Jeonju, Republic of Korea \\ ${ }^{6}$ Department of Surgery, Chonbuk National University Medical School, Jeonju, Republic of Korea \\ *These authors have contributed equally to this work \\ Correspondence to: Hyun Goo Woo, e-mail: hg@ajou.ac.kr
}

Keywords: olaparib, PARP1, FOXO3A, prognosis, G2/M arrest

Received: May 27, $2015 \quad$ Accepted: October 22, $2015 \quad$ Published: November 02,2015

\section{ABSTRACT}

Poly (ADP-ribose) polymerase1 (PARP1) has been reported as a possible target for chemotherapy in many cancer types. However, its action mechanisms and clinical implications for gastric cancer survival are not yet fully understood. Here, we investigated the effect of PARP1 inhibition in the growth of gastric cancer cells. PARP1 inhibition by Olaparib or PARP1 siRNA could significantly attenuate growth and colony formation of gastric cancer cells, and which were mediated through induction of $\mathrm{G2} / \mathrm{M}$ cell cycle arrest but not apoptosis. FOX03A expression was induced by PARP1 inhibition, suggesting that FOX03A might be one of downstream target of the PARP1 effect on gastric cancer cell growth. In addition, by performing tissue microarrays on the 166 cases of gastric cancer patients, we could observe that the expression status of PARP1 and FOX03A were significantly associated with overall survival (OS) and relapse-free survival (RFS). Strikingly, combined expression status of PARP1 and F0X03A showed better prediction for patient's clinical outcomes. The patient group with PARP1+/FOXO3A- expression had the worst prognosis while the patient group with PARP1-/FOXO3A+ had the most favorable prognosis (OS: $P=6.0 \times 10^{-9}$, RFS: $P=2.2 \times 10^{-8}$ ). In conclusion, we suggest that PARP1 and F0X03A play critical roles in gastric cancer progression, and might have therapeutic and/or diagnostic potential in clinic.

\section{INTRODUCTION}

Gastric cancer is one of the most common malignancies with heterogeneous clinical outcome [1], but its mechanisms leading to development and/or progression of tumors remain unclear. PARP1 is a kind of polymerase that can conjugate ADP from NAD+ to target proteins such as histones and p53, to activate their functions in
DNA repair response to DNA damage. PARP1 has been known to play an important role in tumor development in breast, ovary, and skin. Moreover, in most of breast and ovarian cancer patients (about 80\%), BRCA gene, another DNA repair gene, is frequently mutated [2]. As a consequence, the expression of PARP1 is up-regulated to compensate the impaired DNA repair and the tumor cells can survive and progress despite of their presence of DNA 
damage [2-4]. Therefore, PARP1 is thought of as one of therapeutic targets for the development of anti-cancer treatments particularly for BRCA-mutated tumors, and a variety of clinical trials are actively in progress [5-11]. However, recent studies have shown that the expression of PARP1 protein can predict poorer prognosis regardless of the existence of a BRCA mutations [12-16], although its action mechanisms were not fully established. Recently, PARP1 inhibition has been addressed to attenuate the AKT-associated phosphorylation of forkhead box $\mathrm{O}$ (FOXO) transcription factors $[17,18]$. Of these FOXO transcription factors, FOXO3A has been known as a downstream target of serine/threonine protein kinase B (PKB)/AKT. Phosphorylated FOXO3A by AKT interacted with 14-3-3, resulting in faster degradation of FOXO3A protein $[19,20]$. When FOXO3A is activated by inhibition of PI3K/AKT pathway, FOXO3A can promote a wide range of cellular effects including cell cycle arrest, induction of autophagy, sensitization to chemotherapeutics, inhibition of metastasis and cell differentiation, and apoptotic cell death [21, 22]. Indeed, decreased expression of FOXO3A protein was associated with tumor progression in various malignancies [23, 24]. Moreover, clinically used drugs like paclitaxel, imatinib, and doxorubicin have shown therapeutic effects through activation of FOXO3A and its targets [25]. Collectively, PARP1 has been implicated in AKT activity, and the FOXO3A phosphorylation by AKT causes its nuclear exclusion and degradation, resulting in the suppression of its transcriptional activity. Therefore, we hypothesized that PARP1 and FOXO3A may interact together and play critical roles in cancer progression. Moreover, to our knowledge, the functional and clinical roles of PARP1 in gastric cancer were not evaluated vigorously yet.

With respect to these, in the present study, we aimed to investigate whether the expressions of PARP1 and FOXO3A have functional and clinical significance in gastric cancer. By performing cell culture experiments, we could observe that PARP1 inhibition significantly attenuated gastric cancer cell growth, and which were mediated through FOXO3A expression. Furthermore, by performing tissue microarrays on the 166 cases of gastric cancer patients, we demonstrated the prognostic predictability of the expression status of PARP1 and FOXO3A in gastric cancer. Our results may provide new biological and clinical insights on the expressions of PARP1 and FOXO3A in gastric cancer progression.

\section{RESULTS}

\section{PARP1 inhibition can suppress the growth of gastric cancer cells}

Tumor-suppressive activity of the PARP inhibitor, Olaparib, was evaluated by using different methods of MTT assay, cell counting, and colony formation assays in the three human gastric cancer cell lines of MKN28, MKN74, and NCI-N87. Treatment of Olaparib showed significant suppression of cancer cell growth in a dose-dependent manner (Figure 1A, top). After $72 \mathrm{~h}$ incubation, IC50 of Olaparib was approximately $10 \mu \mathrm{M}$ in the three different cell lines. Cell counting assays confirmed the time-dependent growth inhibition by Olaparib treatment. The cell numbers after treatment with Olaparib $(2.5 \mu \mathrm{M})$ for 5 days were significantly lower than those of the control cells (Figure 1A, middle). Colony formation ability was also decreased by Olaparib treatment (Figure 1A, bottom). In addition, to confirm the Olaparib effect through PARP1 inhibition, we performed siRNAmediated knock-down experiments. Similar to Olaparib, knock-down of PARP1 by siRNA significantly inhibited the proliferation and colony formation of gastric cancer cells (Figure 1B and 1C). However, treatment of Olaparib in the PARP1 siRNA-transfected cells had no effect on cell proliferation, which may indicate that the tumorsuppressive effect of Olaparib is through inactivation of PARP1 (Figure 1D). Supporting this, a previous study has demonstrated that PARP1/2 can be trapped into a specific DNA sites causing direct cytotoxicity, suggesting that PARP1 is essential in Olaparib-mediated tumor suppression [26]. Therefore, we suggest that PARP1 inhibition by Olaparib can suppress the growth of human gastric cancer cells.

\section{PARP1 inhibition induce FOXO3A expression and $\mathrm{G} 2 / \mathrm{M}$ cell cycle arrest}

As described in the Introduction, FOXO3A is thought as one of putative effector downstream target of PARP1. To evaluate this hypothesis, we examined the effect of Olaparib on the expression of FOXO3A. Western blot analysis demonstrated that the treatment of Olaparib up-regulate FOXO3A expression in both MKN28 and MKN74 cells in a dose-dependent manner (Figure 2A). In addition, when Olaparib was treated to the FOXO3A knock-down cells, the Olaparib-mediated growth inhibition was rescued, in part, by knock-down of FOXO3A expression (Figure 2B). By contrast, knockdown of FOXO3A had no effect on the expression levels of PARP1 mRNAs as well as proteins (Figure 2C, 2D). These results consistently support that FOXO3A is one of downstream target for the tumor-suppressive effect of PARP1 inhibitor. Taken together, we suggest that tumorsuppressive effect of PARP1 inhibition is mediated, at least in part, by FOXO3A activation, although further studies might be required to address direct signaling mechanisms between PARP1 and FOXO3A.

FOXO3A has been known to harbor multifaceted cell functions including cell cycle regulation, apoptosis, autophagy, and DNA repair $[18,27]$. With this concern, we next examined whether the effect of PARP1 inhibition on cancer growth is mediated through activation of apoptotic 
A
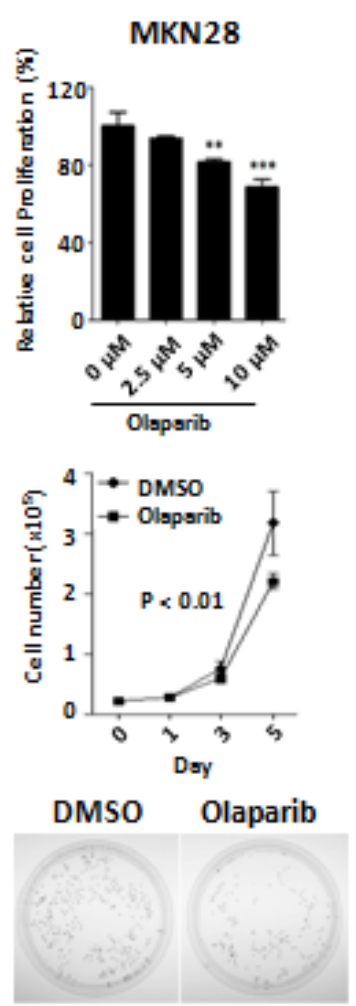

B
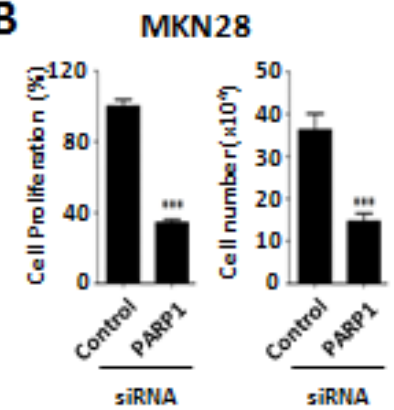

C

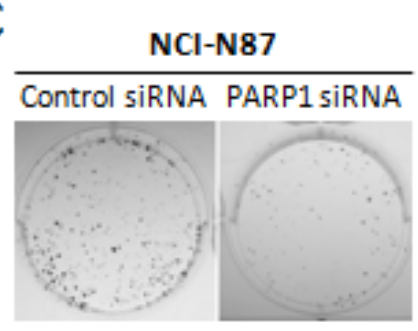

MKN74
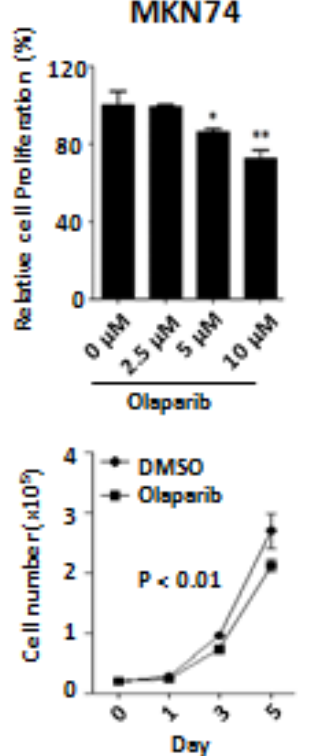

DMSO
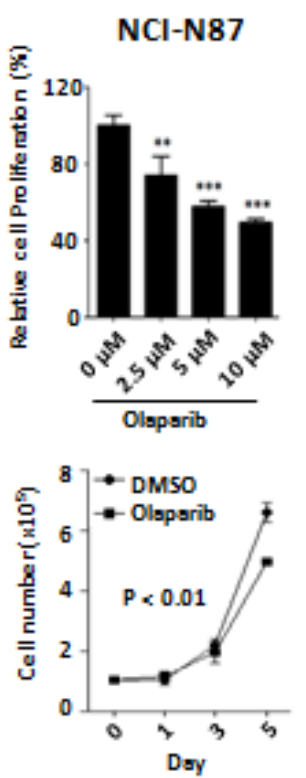

DMSO Olaparib
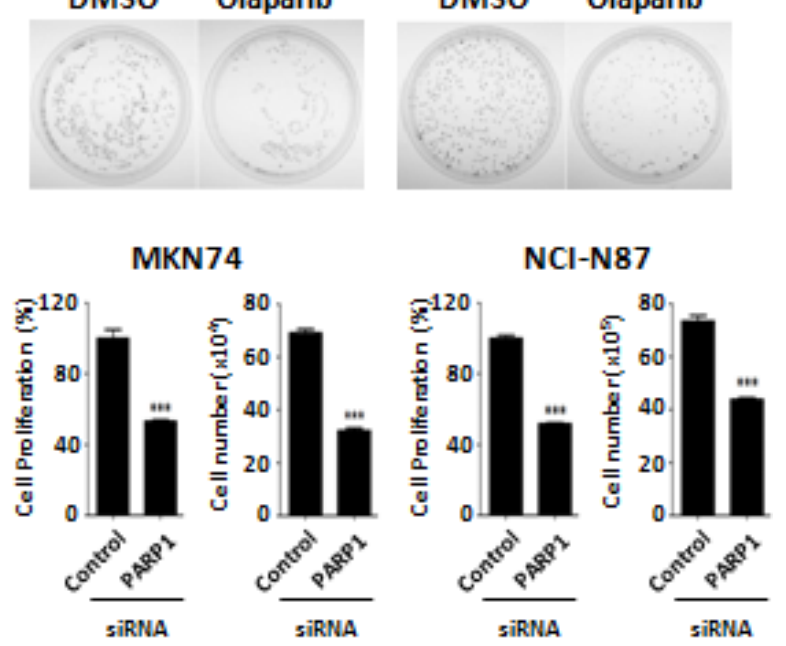

D

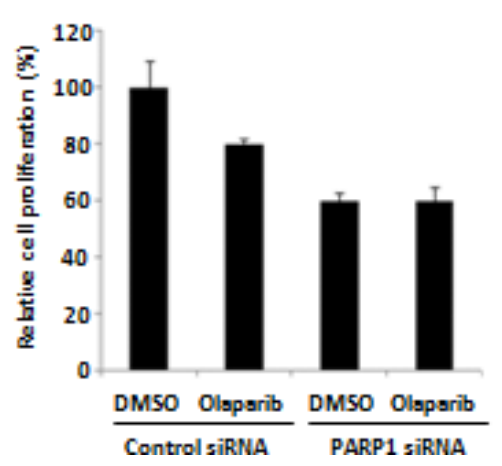

Figure 1: Anti-proliferative activity of Olaparib and PARP1 siRNA against gastric cancer cells. (A) Dose-dependent effect of Olaparib $(0,2.5,5$, and $10 \mu \mathrm{M})$ after $72 \mathrm{~h}$ incubation are shown in MKN28, MKN74, and NCI-N87 cells. Relative cell proliferation rate by Olaparib compared to the control (DMSO) treatment was determined by an MTT assay (top). Cell counting assays show the time- dependent effect of Olaparib $(0,2.5$, and $5 \mu \mathrm{M})$ for $0,1,3$, or 5 days (middle). Colony formation assays are performed on the cells treated with Olaparib ( 0 and $2.5 \mu \mathrm{M})$ for 14 days as described in the "Materials and Methods" (bottom). (B) Cells are transfected with control or PARP1 siRNA (30 nM) for 4 days and cell proliferation is determined by a cell counting assay and an MTT assay. (C) Colony formation assays are performed using NCI-N87 cells transfected with control or PARP1 siRNA (100 nM) for 14 days. (D) Olaparib $(5 \mu \mathrm{M}$, for $72 \mathrm{~h}$ ) is treated on the MKN28 cells transfected with control or PARP1 siRNA, and the cell viability is determined by MTT assay. Results shown are from one representative assay out of three biological replicates. Data are the mean \pm S.D. $(n=3) .{ }^{*} P<0.05$, $* * P<0.01$ with respective control. 
process. However, we could not observe the expression of pro-apoptotic proteins such as cleaved form Caspase 3 or Bax by Olaparib treatment, which may suggest that the Olaparib effect is not likely to be mediated by apoptotic process (Figure 2E).
On the other hand, FOXO3A has been known to trigger DNA repair in response to DNA damage by activating cell cycle arrest [28-30]. With this concern, we evaluated the effect of Olaparib in cell cycle system by performing flow cytometry analysis. Treatment of
A

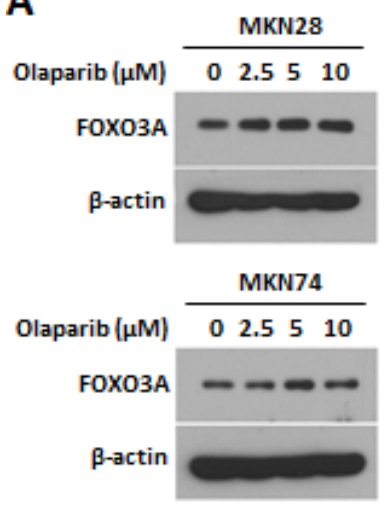

B

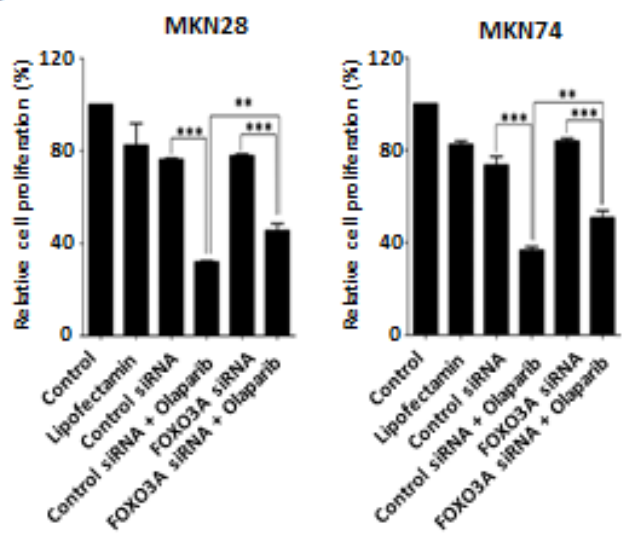

C

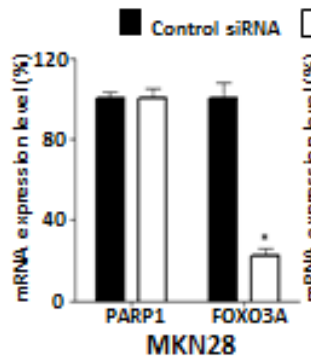

E

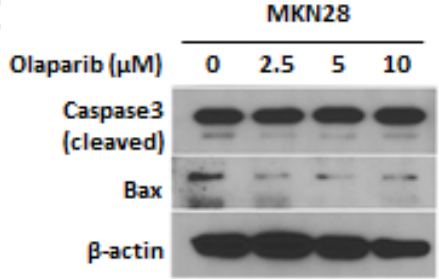

$\mathbf{F}$

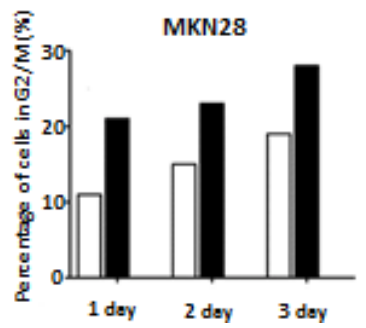

D

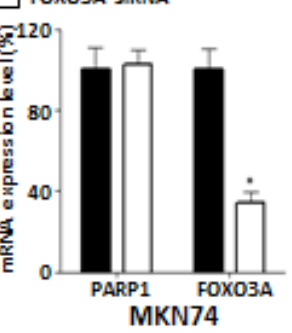

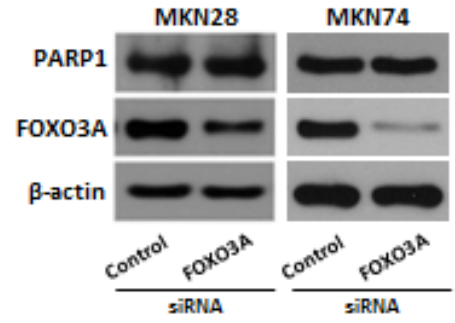

G
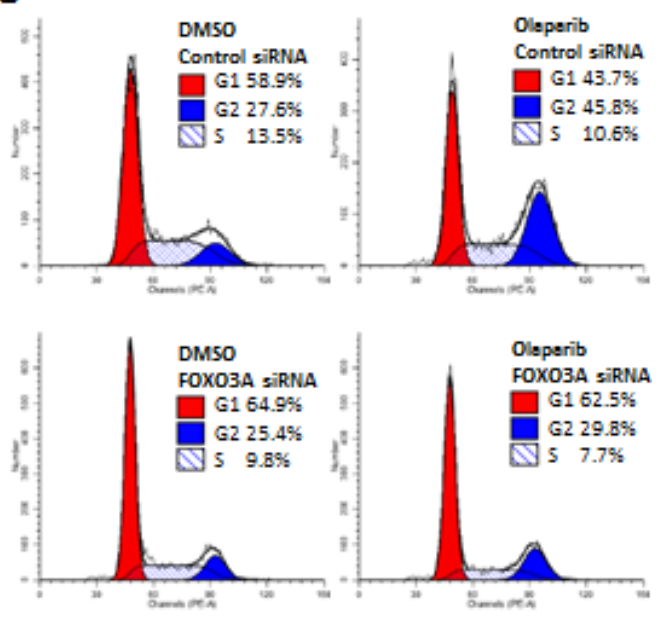

Figure 2: PARP1 inhibition induce G2/M cell cycle arrest and FOXO3A expression. (A) Western blotting results of cells treated with Olaparib $(0,2.5,5$, and $10 \mu \mathrm{M})$ for $72 \mathrm{~h}$. $\beta$-actin is used as a gel-loading control. (B) Olaparib $(10 \mu \mathrm{M})$ or control vehicle (DMSO) are treated for $72 \mathrm{~h}$ in the MKN28 and MKN74 cells transfected with non-target control or FOXO3A siRNA (30 nM), and the effect on cell proliferation is determined by an MTT assay. (C) The expressions of PARP1 and FOXO3A mRNAs are measured by real-time qPCR in the MKN28 and MKN74 cells transfected with non-target control or FOXO3A siRNAs (30 nM for 24 h). Data are the mean \pm S.D. $(n=3) .{ }^{*} P<0.05$ with respective control. (D) The expressions of PARP1 and FOXO3A proteins are measured by western blot analysis in the MKN28 and MKN74 cells transfected with non-target control or FOXO3A siRNAs (30 nM for $72 \mathrm{~h}$ ). (E) Western blotting results of cleaved Caspase 3 and Bax expression in the MKN28 cells treated with Olaparib $(0,2.5$, 5, or $10 \mu \mathrm{M})$ for 3 days. (F) Flow cytometry results of MKN28 cells treated with Olaparib $(0$ or $10 \mu \mathrm{M})$ for 1, 2, or 3 days. (G) Olaparib $(10 \mu \mathrm{M})$ is treated for 48 h on the MKN28 cells transfected with control or FOXO3A siRNA. Distribution of cell cycle is analyzed using flow cytometry. These results are from one representative assay of three biological replicates. Data are mean \pm S.D. $(n=3)$. ${ }^{*} P<<0.05,{ }^{*} * *<0.01$ with respective control. 
Olaparib $(10 \mu \mathrm{M})$ significantly increased the percentage of $\mathrm{G} 2 / \mathrm{M}$ phase cells $(21 \%, 23 \%$, and $28 \%$, at day 1,2 , and 3 , respectively) compared to those of control cells $(11 \%, 15 \%$, and $19 \%$ at day 1,2 , and 3 , respectively) (Figure 2F). In addition, when FOXO3A expression was knocked down by siRNAs, the percentage of cells with G2/M arrest by Olaparib was significantly decreased from $45.8 \%$ to $29.8 \%$ (Figure $2 \mathrm{G}$ ). These results consistently suggest that PARP1 inhibition can induce G2/M cell cycle arrest through activation of $\mathrm{FOXO} 3 \mathrm{~A}$ in gastric cancer cells.

Previously, impaired BRCA1/2 genes have been known to play an important role in conferring sensitivity to PARP1 inhibitors, providing a well-accepted DNA repair mechanism for the tumor-suppressive effect of PARP1 inhibitors [3, 7, 31, 32]. Indeed, we have also observed that knock-down of BRCA1 or BRCA2 could sensitize Olaparib effect in MKN28 gastric cancer cells (Supplementary Figure S1). This may imply that the Olaparib treatment might be beneficial especially to the BRCA-impaired gastric cancer patients, although further studies might be required to delineate the functional roles of BRCA genes to PARP1 and FOXO3A signaling.

\section{PARP1 and FOXO3A expressions are associated with clinical outcomes of gastric cancer patients}

Confirming the biological relevance of the PARP1 and FOXO3A expression in gastric cancer cells, we next evaluated the clinical significance of these genes by performing tissue microarray assays in the 166 cases of gastric cancer patients. Immunohistochemical staining indicated that the expressions of PARP1 and FOXO3A were mainly localized to the nuclei of tumor cells with weak expression in the cytoplasm, therefore, we considered only the nuclear expression of PARP1 and FOXO3A in the analysis (Figure 3A). By performing receiver operating characteristic curve (ROC) analysis for patients' survival, the cutoffs for positive immunostaining of PARP1 and FOXO3A were determined to have the highest likelihood ratio by selecting the cutoff values at the highest and the lowest AUC (area under the curve), respectively. Based on this analysis, PARP1-positive group was determined with cutoff score 7, and FOXO3Apositive group was determined with cutoff score 6 (Supplementary Figure S2).

Clinico-pathological features and the expression status of PARP1 and FOXO3A in the cohort of gastric cancer patients were summarized in Table 1. Overall, positive staining of PARP1 and FOXO3A proteins were observed in 54\% (89 out of 166) and 19\% (32 out of 166) in the cohort, respectively. PARP1 expression was more frequent in the patients with higher tumor stage $(P<0.001)$, the presence of tumor invasion $(P<0.001)$, lymph node metastasis $(P<0.001)$, and venous invasion $(P=0.017)$. In contrast, FOXO3A expression was more frequent in the patients with low tumor stage $(P=0.019)$ and early gastric cancers $(\mathrm{EGC})(P=0.042)$. Thus, we could suggest that PARP1 expression is associated with aggressive phenotypes while FOXO3A expression is associated with less aggressive phenotypes of gastric cancers.

Univariate Cox regression analysis has revealed several clinical features associated with shorter overall survival (OS) and/or recurrence-free survival (RFS), which included the preoperative serum levels of CEA and CA 19-9, tumor stage, lymph node metastasis, tumor invasion classification, and venous invasion (Table 2). In addition, the patient group with PARP1-positive tumors showed significant shorter OS (Hazard Ratio HR; 2.19, 95\% CI; $1.424-3.370, P<0.001)$ and RFS $(H R ; 2.143,95 \% \mathrm{CI}$; $1.406-3.265, P<0.001)$. Vice versa, the patients with FOXO3A-negative tumors showed shorter OS (HR; 3.893, 95\% CI; 1.800-8.416, $P<0.001)$ and RFS $(H R ; 3.453$, 95\% CI; 1.673-7.127, $P<0.001)$. Kaplan-Meier analyses also revealed that these features (i.e., tumor stage, PARP1, and FOXO3A) could predict prognostic outcomes of OS and RFS, respectively (log-rank test, $P<0.001$, Figure 3B).

In addition, to verify whether the prognostic significance of the PARP1 and FOXO3A expressions are independent each other, we performed KaplanMeier plot analyses for the subgroups classified based on the expression status of PARP1 or FOXO3A, respectively. We could observe that the expression status of PARP1 predicted prognostic subgroups regardless of their expression status of FOXO3A (Supplementary Figure S3A, S3B). Likewise, the expression status of FOXO3A could predict prognostic subgroups regardless of their PARP1 expression status (Supplementary Figure S3C, S3D). Consistently, multivariate analysis also demonstrated that tumor stage and the expressions PARP1 and FOXO3A are independent prognostic indicators for OS and RFS (Table 2). Therefore, we could suggest that the PARP1 and FOXO3A expressions are significantly helpful in predicting clinical outcomes of gastric cancer patients.

In Table 1, we have observed that the expressions of PARP1 and FOXO3A proteins were significantly associated with Lauren classification $(P=0.035$ and $P=0.007$, respectively). This may raise a possibility that the Olaparib effect and/or the prognostic association of PARP1 and FOXO3A might be different among the subtypes of Lauren classification. To address this issue, Kaplan-Meier plot analyses were performed on the each of subtypes of Lauren classification. Regardless of the subtype, we could observe that PARP1-positive tumors have poorer OS and RFS, while the FOXO3A-positive tumors have favorable OS and RFS, respectively (Supplementary Figure S4). In addition, we examined whether PARP1 inhibition has different effects among the tumor types. Treatment of Olaparib suppressed the growth of both diffuse type-derived gastric cancer cells (i.e., MKN45 and KATOIII) as well as intestinal type-derived cells (i.e., MKN28 and MKN74), 
Table 1: Clinico-pathological features and the expression status of PARP1 and FOXO3A in gastric cancer patients $(n=166)$

\begin{tabular}{|c|c|c|c|c|c|c|}
\hline \multirow{2}{*}{\multicolumn{2}{|c|}{ Characteristic }} & \multirow{3}{*}{$\begin{array}{c}n \\
50\end{array}$} & \multicolumn{2}{|c|}{ PARP1 } & \multicolumn{2}{|c|}{ FOXO3A } \\
\hline & & & \multirow{2}{*}{$\frac{\text { Positive }}{21(42 \%)}$} & \multirow{2}{*}{$\frac{\boldsymbol{P} \text {-value }}{0.049}$} & \multirow{2}{*}{$\frac{\text { Positive }}{6(12 \%)}$} & \multirow{2}{*}{$\frac{\boldsymbol{P} \text {-value }}{0.119}$} \\
\hline Age (years) & $<60 \mathrm{y}$ & & & & & \\
\hline & $\geq 60 y$ & 116 & $68(59 \%)$ & & $26(22 \%)$ & \\
\hline \multirow[t]{2}{*}{ Sex } & Female & 41 & $24(59 \%)$ & 0.466 & $7(17 \%)$ & 0.68 \\
\hline & Male & 125 & $65(52 \%)$ & & $25(20 \%)$ & \\
\hline \multirow[t]{2}{*}{ CEA* } & Normal & 106 & $52(49 \%)$ & 0.088 & $18(17 \%)$ & 0.428 \\
\hline & Elevated & 30 & $20(67 \%)$ & & $7(23 \%)$ & \\
\hline \multirow[t]{2}{*}{ CA19-9* } & Normal & 120 & $63(53 \%)$ & 0.778 & $24(20 \%)$ & 0.182 \\
\hline & Elevated & 16 & $9(56 \%)$ & & $1(6 \%)$ & \\
\hline \multirow[t]{2}{*}{ TNM stage } & I \& II & 73 & $28(38 \%)$ & $<0.001$ & $20(27 \%)$ & 0.019 \\
\hline & III \& IV & 93 & $61(66 \%)$ & & $12(13 \%)$ & \\
\hline \multirow[t]{2}{*}{ Tumor invasion } & EGC & 31 & $8(26 \%)$ & $<0.001$ & $10(32 \%)$ & 0.042 \\
\hline & AGC & 135 & $81(60 \%)$ & & $22(16 \%)$ & \\
\hline \multirow[t]{2}{*}{ LN metastasis } & Absence & 56 & $18(32 \%)$ & $<0.001$ & $14(25 \%)$ & 0.182 \\
\hline & Presence & 110 & $71(65 \%)$ & & $18(16 \%)$ & \\
\hline \multirow[t]{2}{*}{ Venous invasion } & Absence & 136 & $67(49 \%)$ & 0.017 & $27(20 \%)$ & 0.689 \\
\hline & Presence & 30 & $22(73 \%)$ & & $5(17 \%)$ & \\
\hline \multirow[t]{6}{*}{ WHO classification } & Tubular & 115 & $70(61 \%)$ & 0.005 & $28(24 \%)$ & 0.045 \\
\hline & SRC & 18 & $5(28 \%)$ & & $1(6 \%)$ & \\
\hline & Mucinous & 17 & $4(24 \%)$ & & $1(6 \%)$ & \\
\hline & Mixed & 12 & $6(50 \%)$ & & $0(0 \%)$ & \\
\hline & Papillary & 2 & $2(100 \%)$ & & $1(50 \%)$ & \\
\hline & Neuroendocrine & 2 & $2(100 \%)$ & & $1(50 \%)$ & \\
\hline \multirow[t]{3}{*}{ Histologic grade ${ }^{* *}$} & WD & 10 & $5(50 \%)$ & 0.207 & $4(40 \%)$ & 0.193 \\
\hline & MD & 64 & $44(69 \%)$ & & $18(28 \%)$ & \\
\hline & $\mathrm{PD}$ & 43 & $23(53 \%)$ & & $7(16 \%)$ & \\
\hline \multirow[t]{3}{*}{ Lauren classification } & Intestinal & 73 & $43(59 \%)$ & 0.035 & $20(27 \%)$ & 0.007 \\
\hline & Diffuse & 72 & $31(43 \%)$ & & $6(8 \%)$ & \\
\hline & Mixed & 21 & $15(71 \%)$ & & $6(29 \%)$ & \\
\hline \multirow[t]{2}{*}{ FOXO3A } & Positive & 32 & $23(72 \%)$ & 0.021 & & \\
\hline & Negative & 134 & 66 (49\%) & & & \\
\hline
\end{tabular}

Abbreviations: CEA, carcinoembryonic antigen; LN, lymph node; WD, well differentiated; MD, moderately differentiated; PD, poorly differentiated; SRC, signet ring cell carcinoma; EGC, early gastric cancer; AGC, advanced gastric cancer; *; Preoperative serum level of CEA or CA19-9 were not measured in 30 patients, respectively. **; Histologic grade was applied primarily to tubular and papillary carcinomas according to the WHO histological classification of gastric tumors. 
suggesting that Olaparib is effective to suppress gastric cancer growth independent of the subtypes of Lauren classification (Supplementary Figure S5).

Next, to further verify the reliability and significance of the prognostic values of PARP1 and FOXO3A expression, we evaluated whether the intensity scores of PARP1 or FOXO3A expression are correlated with clinical outcomes. We measured the intensity of immunohistochemical staining by Allred scores for PARP1 (Mean Allred score \pm standard error; $4.8 \pm 0.2$ ) and FOXO3A (Mean Allred score \pm standard error; $3.8 \pm 0.2$ ). The patients were sub-classified based on the Allred scores for immunostaining intensities of PARP1 (scores 0-3, 4-5, 6-8) or FOXO3A (scores 0-2, $3-6,7-8)$, respectively. We found that the patient group with higher scores of PARP1 showed poorer prognostic outcomes of OS and RFS ( $P<0.001$, Figure 4A). Vice versa, the patient group with higher scores of FOXO3A showed more favorable clinical outcomes of OS and RFS $(P<0.001$, Figure 4B).

On the other hand, we could observe that the PARP1-positive tumors frequently co-expressed FOXO3A protein (23 out of 32, $P=0.021$, Chi-square test, Table 1 ). Likewise, the Allred scores of PARP1 and FOXO3A

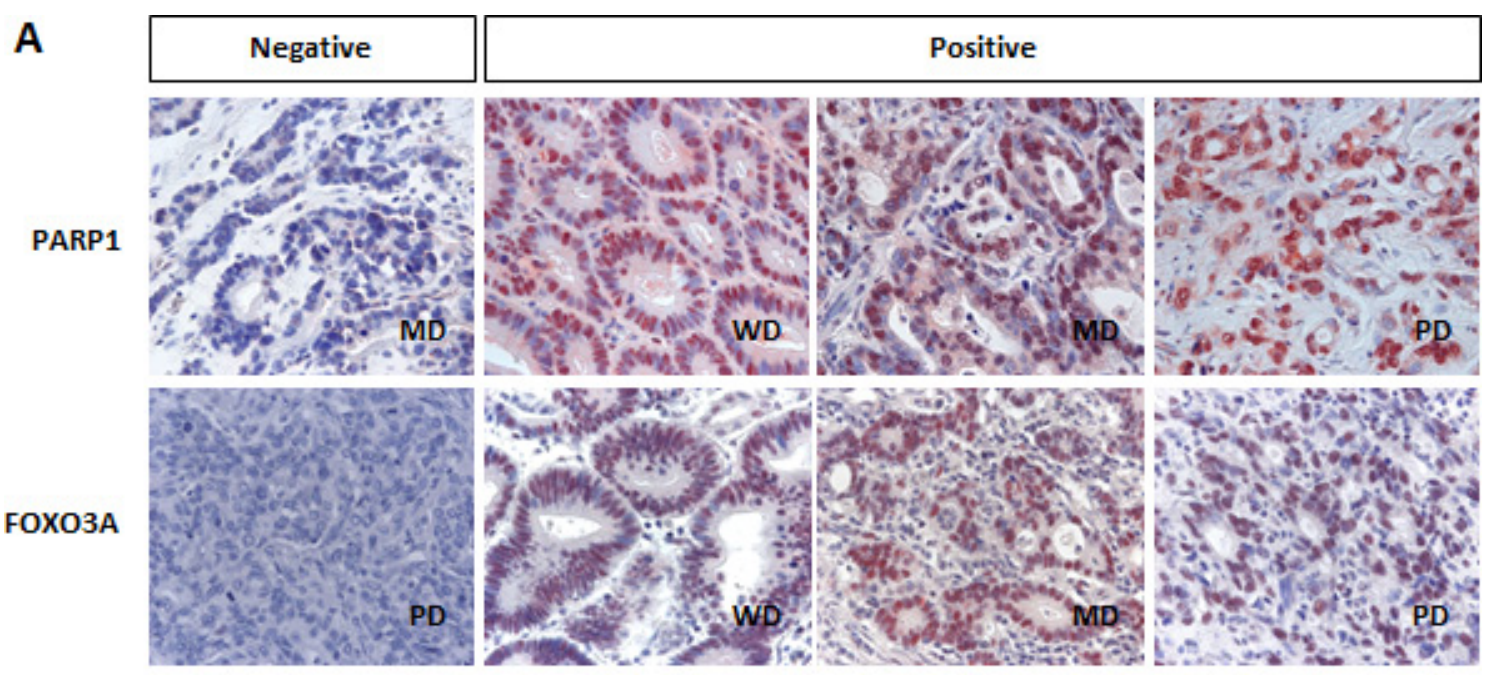

B
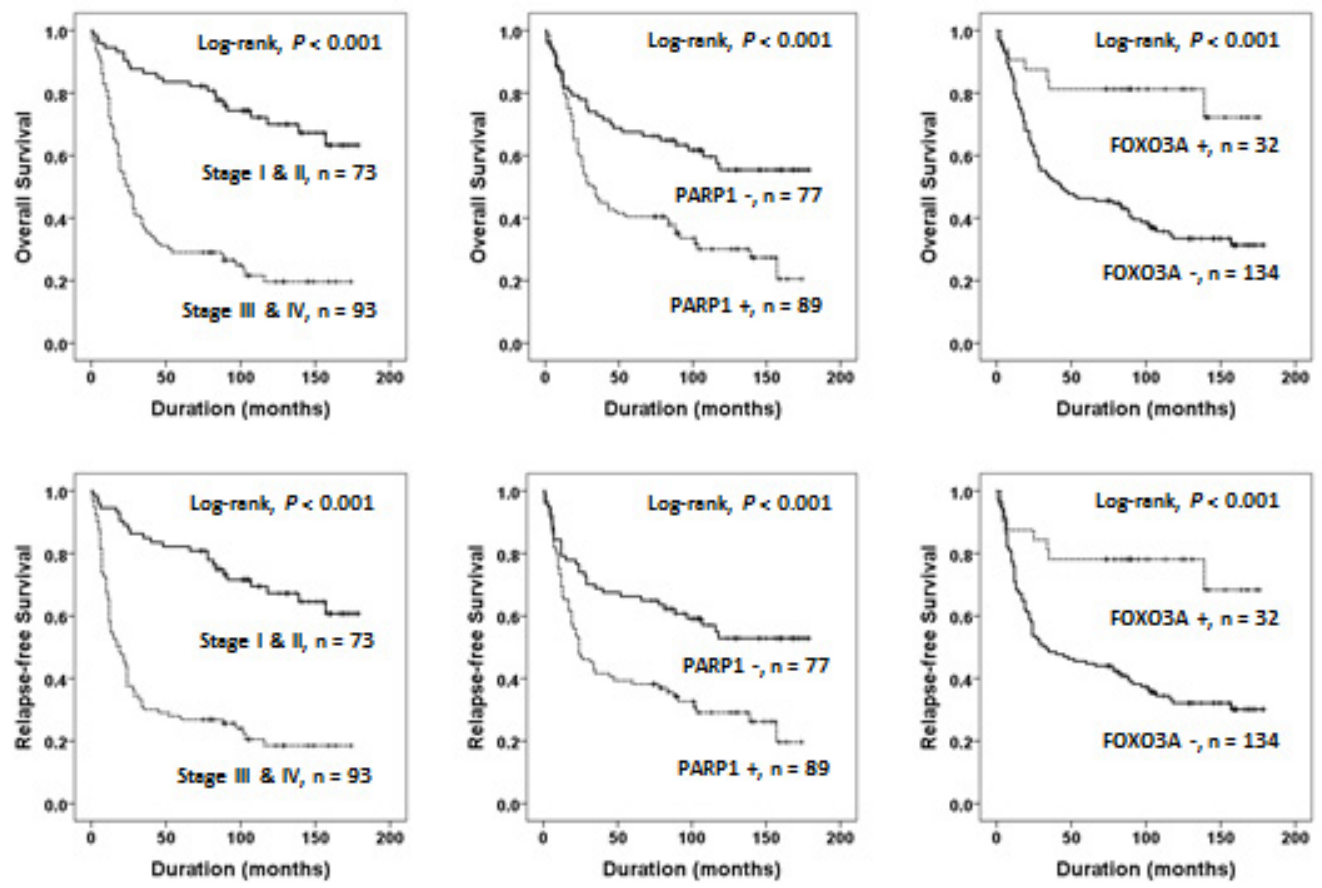

Figure 3: PARP1 and FOXO3A expression are associated with clinical outcomes of gastric cancer. (A) Immunohistochemical expression of PARP1 and FOXO3A in well differentiated (WD), moderately differentiated (MD), and poorly differentiated (PD) gastric adenocarcinomas. (B) Kaplan-Meier plot analyses of OS (top) and RFS (bottom) for the subgroups classified based on the tumor stage (stage I and II vs. III and IV) and the expression status of PARP1 and FOXO3A, respectively. 
Table 2: Univariate and multivariate analysis for relapse-free survival and overall survival in gastric carcinoma patients

\begin{tabular}{|c|c|c|c|c|c|}
\hline \multirow{2}{*}{ Features } & \multirow{2}{*}{$n$} & \multicolumn{2}{|l|}{ OS } & \multicolumn{2}{|l|}{ RFS } \\
\hline & & HR $(95 \%$ CI) & $P$-value & HR $(95 \%$ CI) & $P$-value \\
\hline \multicolumn{6}{|l|}{ Univariate analysis } \\
\hline CEA, elevated ( $v s$. normal) & $30 / 136$ & $2.024(1.230-3.330)$ & 0.006 & $1.917(1.170-3.144)$ & 0.01 \\
\hline CA19-9, elevated (vs. normal) & $16 / 136$ & $2.510(1.376-4.580)$ & 0.003 & $2.275(1.251-4.138)$ & 0.007 \\
\hline TNM stage, III and IV (vs. I and II) & $93 / 166$ & $4.660(2.865-7.581)$ & $<0.001$ & $4.488(2.802-7.186)$ & $<0.001$ \\
\hline Tumor invasion, AGC ( vs. EGC) & $135 / 166$ & $3.539(1.711-7.320)$ & $<0.001$ & $3.767(1.823-7.785)$ & $<0.001$ \\
\hline LN metastasis, presence ( $v s$. absence) & $110 / 166$ & $3.696(2.178-6.271)$ & $<0.001$ & $3.737(2.230-6.261)$ & $<0.001$ \\
\hline Venous invasion, presence ( $v s$. absence) & $30 / 166$ & $2.724(1.705-4.352)$ & $<0.001$ & $2.654(1.666-4.229)$ & $<0.001$ \\
\hline PARP1, positive ( $v s$. negative) & $89 / 166$ & $2.190(1.424-3.370)$ & $<0.001$ & $2.143(1.406-3.265)$ & $<0.001$ \\
\hline FOXO3A, negative (vs. positive) & $134 / 166$ & $3.893(1.800-8.416)$ & $<0.001$ & $3.453(1.673-7.127)$ & $<0.001$ \\
\hline \multicolumn{6}{|l|}{ Multivariate analysis* } \\
\hline TNM stage, III and IV (vs. I and II) & & $3.444(1.922-6.171)$ & $<0.001$ & $3.345(1.918-5.836)$ & $<0.001$ \\
\hline PARP1, positive ( $v s$. negative) & & $1.783(1.090-2.915)$ & 0.021 & $1.756(1.089-2.830)$ & 0.021 \\
\hline FOXO3A, negative (vs. positive) & & $6.958(2.163-22.383)$ & 0.001 & $5.351(1.929-14.845)$ & 0.001 \\
\hline
\end{tabular}

Abbreviations: OS, overall survival; RFS, relapse-free survival; HR, hazard ratio; CEA, carcinoembryonic antigen; LN, lymph node; EGC, early gastric cancer; AGC, advanced gastric cancer. ${ }^{*}$ The variables considered in the multivariate analysis were the pretreatment serum level of CEA and CA19-9, tumor stage, tumor invasion (EGC versus AGC), the presence of lymph node metastasis, venous invasion, and the expression of PARP1 and FOXO3A.

showed significant positive correlation (Spearman's rho $0.382, P<0.001$, Supplementary Figure S6), implying functional link between PARP1 and FOXO3A expression. However, as shown in Table 1, PARP1positive tumors showed aggressive phenotype, while the FOXO3A-positive tumors showed favorable phenotype. This discrepant observation raises a possibility that the oncogenic expression of PARP1 may lead to concomitant expression of FOXO3A as a compensatory mechanism to suppress tumor progression. The tumors expressing PARP1 without counter-balanced FOXO3A expression (i.e., FOXO3A-/ PARP1+) might acquire uncontrolled tumor growth provoking aggressive behavior.

Considering the functional link between PARP1 and FOXO3A, we next sought whether the combined expression status of PARP1 and FOXO3A is better in predicting clinical outcomes of gastric cancer patients. Strikingly, when we stratified the patients based on the combined expression status of PARP1 and FOXO3A, the patient group with PARP1+/FOXO3A- $(n=66)$ showed the worst prognosis while the patients with PARP-/ FOXO3A $+(n=9)$ showed the most favorable prognosis of OS $\left(P=6.0 \times 10^{-9}\right)$ and RFS $\left(P=2.2 \times 10^{-8}\right)$, respectively (Figure $4 \mathrm{C}$ ). The patent group with PARP+/FOXO3A+ $(n=23)$ or the group with PARP1-/FOXO3A- $(n=23)$ showed intermediate prognostic outcomes. These results strongly suggest that the combined expression status of PARP1 and FOXO3A rather than the expression of each gene is better in predicting clinical outcomes of gastric cancer patients.

\section{DISCUSSION}

In the present study, by performing combined analysis of experimental and clinical data, we could demonstrate that PARP1 and FOXO3A are functionally linked and their expression levels are useful in predicting clinical outcomes of gastric cancer patients. We demonstrated that PARP1 inhibition induce G2/M cell cycle arrest but not apoptosis in gastric cancer cells. In addition, FOXO3A was suggested as a downstream target for the tumor-suppressive effect of PARP1 inhibitor.

Indeed, there are a few reports that suggest a possible link between PARP1 and FOXO3A. PARP1 is activated within a few seconds after DNA damage to interact with and PARsylate (add poly ADP ribose) IKK gamma, and which promote cancer cell survival via NF- $\kappa \mathrm{B}$ activation [33]. PARP1 is recruited to DNA damage sites immediately 
A
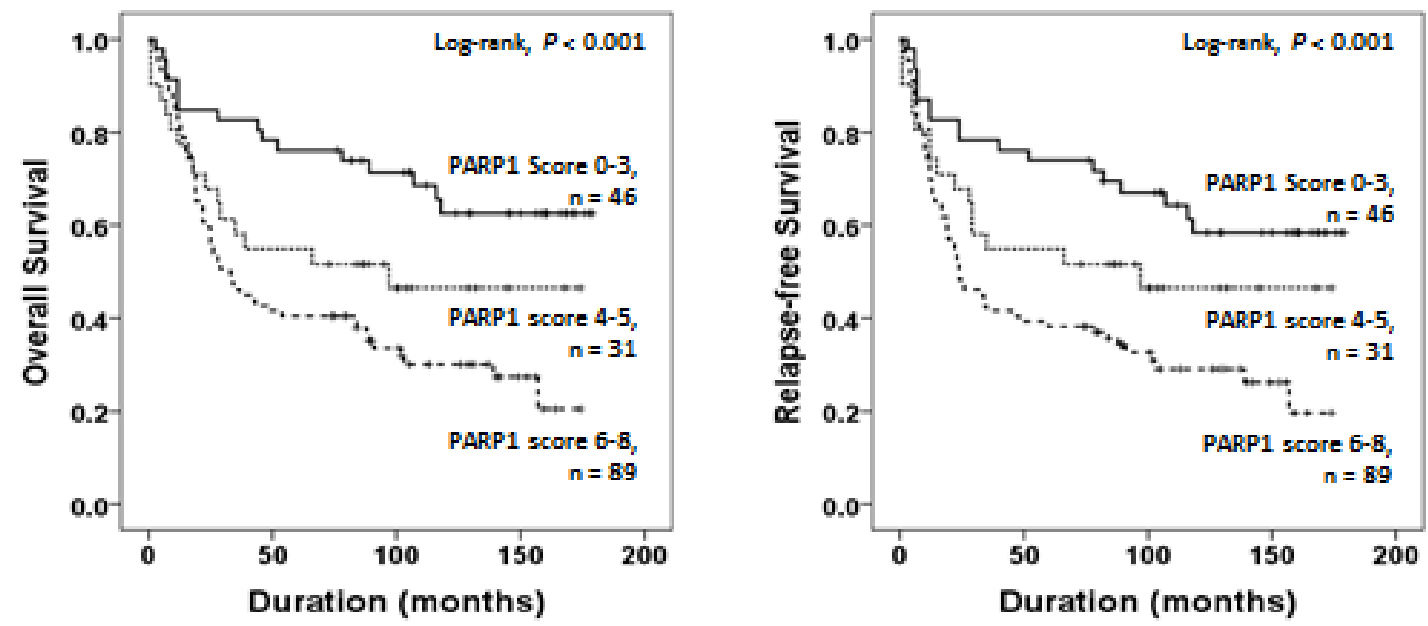

B
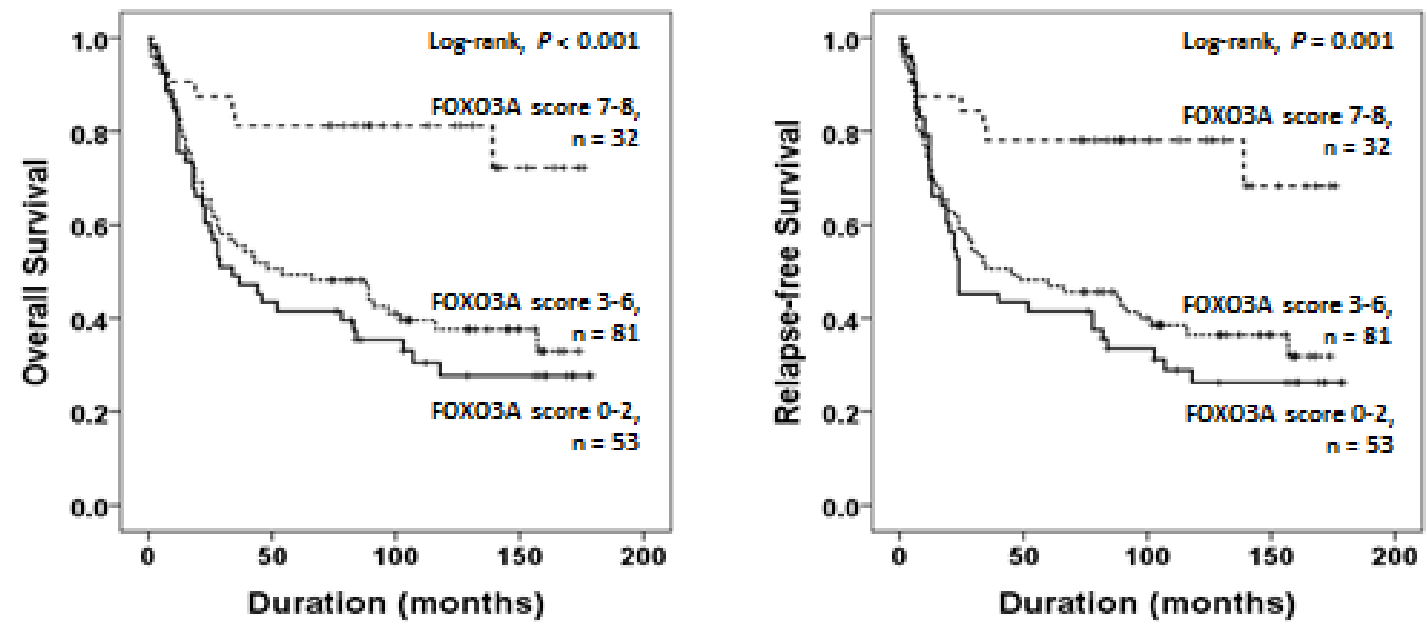

C
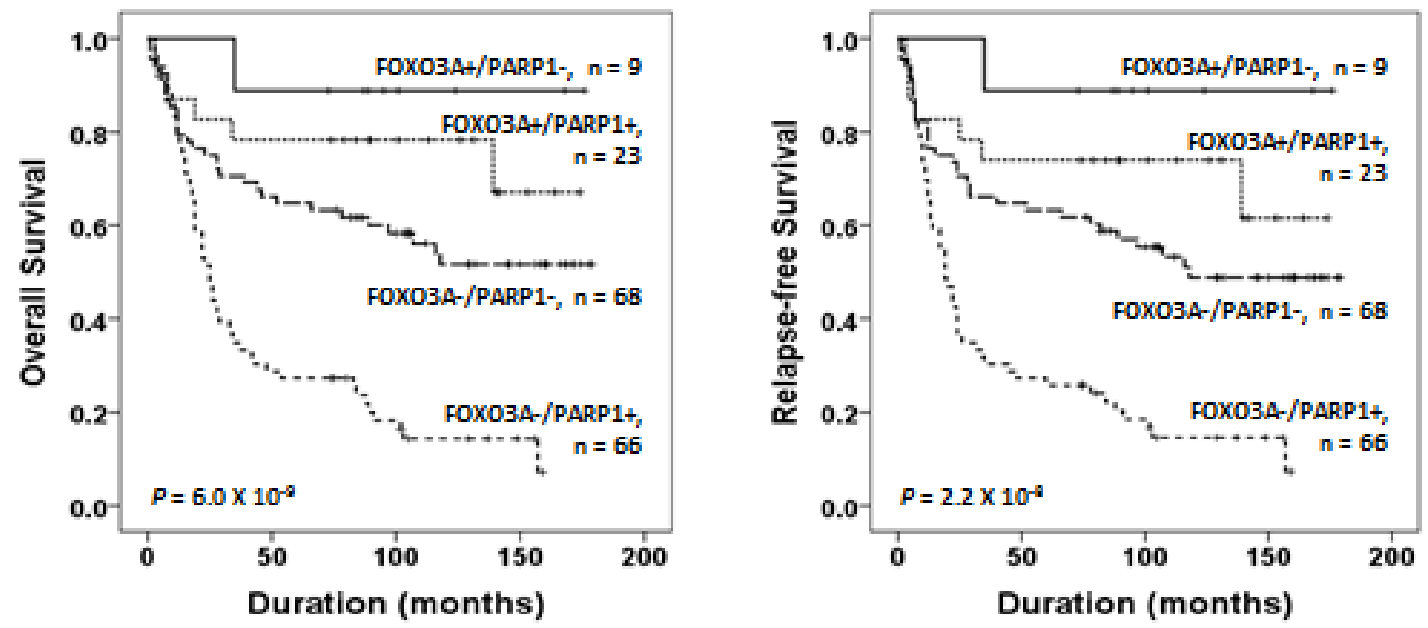

Figure 4: Survival analyses of PARP1 and FOXO3A expression status. (A) Kaplan-Meier plot analyses of OS (left) and RFS (right) for the subgroups classified based on the Allen scores of PARP1 (scores 0-3, 4-5, 6-8) expression. (B) Kaplan-Meier plot analyses for OS (left) and RFS (right) on the subgroups classified based on the Allred scores of FOXO3A (scores 0-2, 3-6, 7-8) expression. (C) Kaplan-Meier survival analyses of OS (left) and RFS (right) for the subgroups classified based on the combined expression status of PARP1 and FOXO3A, i.e., FOXO3A+/PARP1+ $(n=23)$, FOXO3A+/PARP1- $(n=9)$, FOXO3A-/PARP1+ $(n=66)$, FOXO3A-/PARP1- $(n=68)$. The $p$-values presented in $(\mathrm{C})$ indicate the statistical significance of the log-rank test for survival among the 4 subgroups. 
and forms interactions with a variety of nuclear DNA repair-related proteins such as ATM and PIASy [34]. This suggests that PARP1 inhibition can inhibit NF- $\kappa \mathrm{B} /$ IKK-mediated pro-survival signaling in cancer cells. On the other hand, it has been suggested that ubiquitination by IKK beta can activate FOXO3A in vitro and in vivo $[35,36]$. Moreover, PARP1 inhibitors could attenuate AKT phosphorylation via up-regulation of PHLPP1 [37]. AKT is known to phosphorylate and degrade FOXO3 proteins $[19,20]$. These results imply that PARP1 can regulate FOXO3A indirectly through NF- $\mathrm{KB}$ or AKT pathways, playing important roles in tumor progression. Supporting this hypothesis, our result successfully demonstrated that FOXO3A is a possible downstream target of PARP1, although further studies might be required to delineate the precise molecular mechanisms on the PARP1 mediated regulation of $\mathrm{FOXO} 3 \mathrm{~A}$ expression.

In addition, we have addressed clinical utilities of PARP1 and FOXO3A expression for gastric cancer patients. Survival analyses using tissue microarrays have successfully demonstrated that the expression of PARP1 and FOXO3A are independent prognostic indicators (OS and RFS) for gastric cancer patients. We have also observed that PARP1 is frequently co-expressed with FOXO3A. According to this discrepant result, we hypothesized that PARP1 expression by oncogenic stimuli may induce FOXO3A expression to attenuate cancer progression as a negative feedback. Thus, if there is a defect in the compensatory expression of FOXO3A, tumors may progress to harbor uncontrolled aggressive behaviors. This raises an idea that induction of FOXO3A in cancer cells could be a new therapeutic strategy for gastric cancer treatment.

In conclusion, our results from cell culture experiments and clinical data analysis consistently indicate that the expression of PARP1 and FOXO3A play pivotal roles in gastric cancer progression. Undoubtedly, PARP1 and FOXO3A can be new prognostic and therapeutic targets for gastric cancer management.

\section{MATERIALS AND METHODS}

\section{Cell culture}

Human gastric carcinoma cell lines (MKN28, MKN74, NCIN87, MKN45, and KATOIII) obtained from the American Type Culture Collection (Manassas, VA) were maintained in RPMI 1640 media supplemented with 10\% FBS (HyClone, Rogan, UT) and 5\% penicillin/ streptomycin at $37^{\circ} \mathrm{C}$ in a humidified $5 \% \mathrm{CO}_{2}$ incubator.

\section{Chemical reagents}

Mouse anti- $\beta$-actin antibody and dimethyl sulfoxide (DMSO), glycerol, glycine, sodium chloride, Thiazolyl Blue Tetrazolium Bromide, Trizma base, and Tween20 were purchased from Sigma (St. Louis, MO). Mouse
anti-PARP1 and rabbit anti-FOXO3A antibodies were purchased from Santa Cruz (Santa Cruz, CA). Rabbit anticaspase3, and rabbit anti-Bax antibody were purchased from Cell Signaling (Danvers, MA). Mouse anti-BRCA1 and rabbit anti-BRCA2 antibodies were from Abcam (Cambridge, MA). Goat anti-mouse and goat anti-rabbit horseradish peroxidase-conjugated IgG were obtained from Jackson ImmunoResearch (West Grove, PA). ECL Western Blotting Detection Reagents were obtained from Genedepot (Barker, TX). Olaparib was obtained from Selleckchem.

\section{siRNA mediated knock-down}

Non-targeting control siRNA and siRNAs against human PARP1, FOXO3A, BRCA1 and BRCA2 were purchased from Santa Cruz Biotechnology (Santa Cruz, CA). Cells were transfected with each siRNA using Lipofectamine 2000 (Invitrogen, CA) according to the manufacturer's instruction.

\section{Colony formation assay}

Cells $\left(0.5 \times 10^{3}\right)$ were seeded in $6 \mathrm{~cm}$ dishes and incubated at $37^{\circ} \mathrm{C}$ in a humidified incubator containing $5 \% \mathrm{CO}_{2}$ for $18 \mathrm{~h}$. After incubation, cells were treated with $\mathrm{DMSO}$ as a control vehicle and the indicated concentration of Olaparib $(2.5 \mu \mathrm{M})$ or PARP1 siRNA (100 nM) for 14 days. Then, the colonies were washed 2 times with PBS, fixed with $3.7 \%$ Paraformaldehyde, and stained with $1 \%$ crystal violet solution in distilled water.

\section{Cell counting assay}

Cells $\left(1 \times 10^{4}\right)$ were seeded in $6 \mathrm{~cm}$ dishes and incubated at $37^{\circ} \mathrm{C}$ in a humidified incubator containing $5 \% \mathrm{CO}_{2}$ for $18 \mathrm{hr}$. After incubation, cells were treated with DMSO as a control vehicle and the indicated concentration of Olaparib $(2.5 \mu \mathrm{M})$ for $0,24,72$, and $90 \mathrm{~h}$. At each time point, cell numbers were counted by using a hemocytometer.

\section{Real-time qPCR}

Total RNA was prepared from cells using the mirVana $^{\mathrm{TM}}$ miRNA Isolation kit (Ambion). cDNA synthesis was performed from $2 \mu \mathrm{g}$ of total RNA via the High Capacity cDNA Reverse Transcription kit (Applied Biosystem). The levels of gene expression were determined using a CF96 ${ }^{\mathrm{TM}}$ Optics Module (BIO-RAD) with the following primers: 5'-CTA CTC GGT CCA AGA TCG-3' (sense for PARP1); 5'-TTG AAA AAG CCC TAA AGG CTC A-3' (antisense for PARP1); 5'-TCT ACG AGT GGA TGG TGC GTT-3' (sense for FOXO3A); 5'-CGA CTA TGC AGT GAC AGG TTG TG-3' (antisense for FOXO3A); 5'-ACC CAG AAG ACT GTG GAT 
GG-3' (sense for GAPDH); 5'-TTC TAG ACG GCA GGT CAG GT-3' (antisense for GAPDH). All reactions were duplicated, and the $2^{-\Delta \Delta \mathrm{Ct}}$ calculation was used for quantification.

\section{Western blotting}

Cells were washed twice with phosphate-buffered saline (PBS) and lysed with lysis buffer containing protease and phosphatase inhibitors at $4{ }^{\circ} \mathrm{C}$ for $30 \mathrm{~min}$. After centrifuging the lysates at $10,000 \mathrm{rpm}$ for 10 min, equivalent amounts of each protein lysates were resolved by $6 \%, 10 \%$, or $12 \%$ SDS-polyacrylamide gel electrophoresis (PAGE) and transferred onto nitrocellulose membranes (Bio-Rad). Membranes were blocked for $1 \mathrm{~h}$ in 3\% bovine serum albumin (BSA) in Tris buffered saline containing $0.1 \%$ Tween 20 (TBST) and then incubated for $1 \mathrm{~h}$ at room temperature or at $4^{\circ} \mathrm{C}$ overnight with primary antibody diluted in TBST containing 3\% BSA. After three washes with TBST, membranes were incubated for $1 \mathrm{~h}$ with horseradish peroxidase-conjugated secondary antibodies (1:3000 or $1: 5000$ dilutions) in TBST containing $1 \%$ BSA. The immunoblots were visualized by an enhanced chemiluminescence kit obtained from West-Q ECL Platinum Solution obtained from GenDEPOT (Barker, TX).

\section{MTT assay}

Cells $\left(2 \times 10^{3}\right)$ were seeded in 96-well plates and incubated at $37^{\circ} \mathrm{C}$ in a humidified incubator containing $5 \%$ $\mathrm{CO}_{2}$ overnight. After treatment of reagents for indicated time period, $20 \mu \mathrm{L}$ MTT solution $(5 \mathrm{mg} / \mathrm{mL}$ in phosphate buffer) was added to each well and incubated for $2 \mathrm{~h}$. The blue crystalline precipitate in each well was dissolved in DMSO $(200 \mu \mathrm{L})$, and the visible absorbance at $595 \mathrm{~nm}$ of each well was quantified using a microplate reader.

\section{Flow cytometry analysis}

After treatment with the Olaparib or FOXO3A siRNA, cells were harvested and washed twice with PBS and fixed in $70 \%$ cold ethanol at $4{ }^{\circ} \mathrm{C}$ overnight. Before analysis, cells were washed twice with PBS, then resuspended with $400 \mu \mathrm{L}$ PBS and treated with $100 \mu \mathrm{g} /$ $\mathrm{mL}$ RNase A (Sigma-Aldrich) and $50 \mu \mathrm{g} / \mathrm{mL}$ propidium iodide (PI) (Sigma-Aldrich). After incubation for $30 \mathrm{~min}$ at $37^{\circ} \mathrm{C}$, the cells were subjected to DNA content analysis. PI fluorescence was analyzed with FACS CantoII (Becton Dickinson). Data from at least 10,000 cells were analyzed with BD FACSDIVA 7.0 (Becton Dickinson). Cell cycle distribution was calculated with ModiFit LT software.

\section{Patients and specimens}

Tissue microarray analysis was performed using gastric adenocarcinoma specimens, which were used in a previous study [38]. In this study, we included 166 cases out of 177 cases of the previous gastric cancer specimens, because the 11 cases were unsuitable for establishing new tissue-microarrays. The patients underwent radical gastrectomy between January 1997 and December 2005 at Chonbuk National University Hospital. The patients' tumor stages (originally 50 cases for the each stage I, II, III, and IV) were matched for the gender, age ( \pm 2 years), and calendar year of surgery- ( \pm 2 years) based on the 6 th edition of AJCC (American Joint Committee on Cancer) staging system. Thereafter, we re-staged the 166 cases according to the guidelines of the 7 th edition of the AJCC staging system and reviewed them according to the criteria of the World Health Organization (WHO) classification. This study was approved by Chonbuk National University Hospital's institutional review board. Informed consent was provided according to the Declaration of Helsinki. The patients were grouped according to their age, sex, preoperative serum carcinoembryonic antigen (CEA) and CA 19-9 levels, tumor stage (I and II vs. III and IV), presence of lymph node metastasis, presence of distant metastasis, presence of venous invasion, histologic types according to the WHO classification, histologic grade of tubular and papillary type carcinomas, Lauren classifications, and tumor invasion [early gastric carcinoma (EGC) vs. advanced gastric carcinoma (AGC)]. The follow-up end point for patients survival and recurrence-free survival was the date of the last contact or the date of death through December 2011.

\section{Tissue microarrays}

Immunohistochemistry was performed on paraffinembedded tissue-microarray blocks. One $3.0 \mathrm{~mm}$ core per case was analyzed in a tissue-microarray. The tissue sections were treated with a microwave antigen retrieval procedure in $\mathrm{pH} 6.0$ sodium citrate buffer for 20 minutes. The following markers were used: PARP1 (H-300) (1:100, Santa Cruz Biotechnology, Santa Cruz, CA), and FOXO3A (D19A7) (1:100, Cell Signaling Technology, Beverly, MA). Two pathologists (Jang KY and Kim KM) have evaluated the immunohistochemical staining of PARP1 and FOXO3A in tissue microarrays by consensus without knowledge of the clinicopathological information. The scoring for the immunostaining for PARP1 and FOXO3A was performed according to the Allred scoring system, which is generally used for evaluation of nuclear expression [39, 40]. The nuclear staining intensity was scored as 0 (no staining), 1 (weak staining), 2 (intermediate staining), or 3 (strong staining). The area of staining was evaluated using the following scores: 0 , no staining cells; $1,1 \%$ of the cells stained positive; $2,2-10 \%$ of the cells stained positive; 3 , $11-33 \%$ of the cells stained positive; $4,34-66 \%$ of the cells stained positive; and 5, 66-100\% of the cells stained positive. Thereafter, the sum of intensity score and proportion score was used for further analysis. The maximum sum score was 8 and the minimum sum score was zero. 


\section{Statistical analysis}

Significance of associations between variable clinicopathologic factors and the expressions of PARP1 or FOXO3A were estimated by Pearson's chi-square test. Univariate and multivariate Cox proportional hazards regression analyses and Kaplan-Meier survival analysis were performed using SPSS software (version 19.0).

\section{CONFLICTS OF INTEREST}

The authors declare none of conflict of interest.

\section{GRANT SUPPORT}

This work was supported by grants from the National Research Foundation of Korea (NRF) funded by the Korea government (MSIP) (NRF-2012R1A5A2048183, 2014R1A6A3A04054307, and No. 2008-0062279), Ajou University School of Medicine, and the Korea Healthcare Technology R\&D Project, Ministry of Health \& Welfare (HI13C2162).

\section{REFERENCES}

1. Siegel R, Naishadham D, Jemal A. Cancer statistics, 2013. CA Cancer J Clin. 2013; 63:11-30.

2. Hoeijmakers JH. DNA damage, aging, and cancer. N Engl J Med. 2009; 361:1475-1485.

3. Bryant HE, Schultz N, Thomas HD, Parker KM, Flower D, Lopez E, Kyle S, Meuth M, Curtin NJ, Helleday T. Specific killing of BRCA2-deficient tumours with inhibitors of poly(ADP-ribose) polymerase. Nature. 2005; 434:913-917.

4. Kummar S, Chen A, Parchment RE, Kinders RJ, Ji J, Tomaszewski JE, Doroshow JH. Advances in using PARP inhibitors to treat cancer. BMC Med. 2012; 10:25.

5. Rouleau M, Patel A, Hendzel MJ, Kaufmann SH, Poirier GG. PARP inhibition: PARP1 and beyond. Nat Rev Cancer. 2010; 10:293-301.

6. Audeh MW, Carmichael J, Penson RT, Friedlander M, Powell B, Bell-McGuinn KM, Scott C, Weitzel JN, Oaknin A, Loman N, Lu K, Schmutzler RK, Matulonis U, Wickens M, Tutt A. Oral poly(ADP-ribose) polymerase inhibitor olaparib in patients with BRCA1 or BRCA2 mutations and recurrent ovarian cancer: a proof-of-concept trial. Lancet. 2010; 376:245-251.

7. Fong PC, Boss DS, Yap TA, Tutt A, Wu P, MerguiRoelvink M, Mortimer P, Swaisland H, Lau A, O'Connor MJ, Ashworth A, Carmichael J, Kaye SB, Schellens JH, de Bono JS. Inhibition of poly(ADP-ribose) polymerase in tumors from BRCA mutation carriers. N Engl J Med. 2009; 361:123-134.

8. Tutt A, Robson M, Garber JE, Domchek SM, Audeh MW, Weitzel JN, Friedlander M, Arun B, Loman N, Schmutzler RK, Wardley A, Mitchell G, Earl H, Wickens M,
Carmichael J. Oral poly(ADP-ribose) polymerase inhibitor olaparib in patients with BRCA1 or BRCA2 mutations and advanced breast cancer: a proof-of-concept trial. Lancet. 2010; 376:235-244.

9. Forster MD, Dedes KJ, Sandhu S, Frentzas S, Kristeleit R, Ashworth A, Poole CJ, Weigelt B, Kaye SB, Molife LR. Treatment with olaparib in a patient with PTEN-deficient endometrioid endometrial cancer. Nat Rev Clin Oncol. 2011; 8:302-306.

10. Plummer R, Jones C, Middleton M, Wilson R, Evans J, Olsen A, Curtin N, Boddy A, McHugh P, Newell D, Harris A, Johnson P, Steinfeldt H, Dewji R, Wang D, Robson L, et al. Phase I study of the poly(ADP-ribose) polymerase inhibitor, AG014699, in combination with temozolomide in patients with advanced solid tumors. Clin Cancer Res. 2008; 14:7917-7923.

11. Clamp A, Jayson G. PARP inhibitors in BRCA mutationassociated ovarian cancer. The Lancet Oncology. 2015; 16:10-12.

12. Staibano S, Pepe S, Lo Muzio L, Somma P, Mascolo M, Argenziano G, Scalvenzi M, Salvatore G, Fabbrocini G, Molea G, Bianco AR, Carlomagno C, De Rosa G. Poly(adenosine diphosphate-ribose) polymerase 1 expression in malignant melanomas from photoexposed areas of the head and neck region. Hum Pathol. 2005; 36:724-731.

13. Barton VN, Donson AM, Kleinschmidt-DeMasters BK, Gore L, Liu AK, Foreman NK. PARP1 expression in pediatric central nervous system tumors. Pediatr Blood Cancer. 2009; 53:1227-1230.

14. Rojo F, Garcia-Parra J, Zazo S, Tusquets I, Ferrer-Lozano J, Menendez S, Eroles P, Chamizo C, Servitja S, RamirezMerino N, Lobo F, Bellosillo B, Corominas JM, Yelamos J, Serrano S, Lluch A, et al. Nuclear PARP-1 protein overexpression is associated with poor overall survival in early breast cancer. Ann Oncol. 2012; 23:1156-1164.

15. Gan A, Green AR, Nolan CC, Martin S, Deen S. Poly(adenosine diphosphate-ribose) polymerase expression in BRCA-proficient ovarian high-grade serous carcinoma; association with patient survival. Hum Pathol. 2013; 44:1638-1647.

16. Hassumi-Fukasawa MK, Miranda-Camargo FA, Zanetti BR, Galano DF, Ribeiro-Silva A, Soares EG. Expression of BAG-1 and PARP-1 in precursor lesions and invasive cervical cancer associated with human papillomavirus (HPV). Pathol Oncol Res. 2012; 18:929-937.

17. Birkenkamp KU, Coffer PJ. FOXO transcription factors as regulators of immune homeostasis: molecules to die for? J Immunol. 2003; 171:1623-1629.

18. Burgering BM, Kops GJ. Cell cycle and death control: long live Forkheads. Trends Biochem Sci. 2002; 27:352-360.

19. Huang H, Tindall DJ. Regulation of FOXO protein stability via ubiquitination and proteasome degradation. Biochim Biophys Acta. 2011; 1813:1961-1964.

20. Tzivion G, Dobson M, Ramakrishnan G. FoxO transcription factors; Regulation by AKT and 14-3-3 proteins. Biochim Biophys Acta. 2011; 1813:1938-1945. 
21. Zhang Y, Gan B, Liu D, Paik JH. FoxO family members in cancer. Cancer Biol Ther. 2011; 12:253-259.

22. Greer EL, Brunet A. FOXO transcription factors at the interface between longevity and tumor suppression. Oncogene. 2005; 24:7410-7425.

23. Yang XB, Zhao JJ, Huang CY, Wang QJ, Pan K, Wang DD, Pan QZ, Jiang SS, Lv L, Gao X, Chen HW, Yao JY, Zhi M, Xia JC. Decreased expression of the FOXO3a gene is associated with poor prognosis in primary gastric adenocarcinoma patients. PLoS One. 2013; 8:e78158.

24. Ni D, Ma X, Li HZ, Gao Y, Li XT, Zhang Y, Ai Q, Zhang P, Song EL, Huang QB, Fan Y, Zhang X. Downregulation of FOXO3a promotes tumor metastasis and is associated with metastasis-free survival of patients with clear cell renal cell carcinoma. Clin Cancer Res. 2014; 20:1779-1790.

25. Yang JY, Hung MC. A new fork for clinical application: targeting forkhead transcription factors in cancer. Clin Cancer Res. 2009; 15:752-757.

26. Murai J, Huang SY, Das BB, Renaud A, Zhang Y, Doroshow JH, Ji J, Takeda S, Pommier Y. Trapping of PARP1 and PARP2 by Clinical PARP Inhibitors. Cancer Res. 2012; 72:5588-5599.

27. Jiang Y, Zou L, Lu WQ, Zhang Y, Shen AG. Foxo3a expression is a prognostic marker in breast cancer. PLoS One. 2013; 8:e70746.

28. Payne SR, Zhang S, Tsuchiya K, Moser R, Gurley KE, Longton G, deBoer J, Kemp CJ. p27kip1 deficiency impairs $\mathrm{G} 2 / \mathrm{M}$ arrest in response to DNA damage, leading to an increase in genetic instability. Mol Cell Biol. 2008; 28:258-268.

29. Li CJ, Chang JK, Chou CH, Wang GJ, Ho ML. The PI3K/ Akt/FOXO3a/p27Kip1 signaling contributes to antiinflammatory drug-suppressed proliferation of human osteoblasts. Biochemical pharmacology. 2010; 79:926-937.

30. Ho KK, Myatt SS, Lam EW. Many forks in the path: cycling with FoxO. Oncogene. 2008; 27:2300-2311.

31. Farmer H, McCabe N, Lord CJ, Tutt AN, Johnson DA, Richardson TB, Santarosa M, Dillon KJ, Hickson I, Knights C, Martin NM, Jackson SP, Smith GC, Ashworth A. Targeting the DNA repair defect in BRCA mutant cells as a therapeutic strategy. Nature. 2005; 434:917-921.
32. Alli E, Sharma VB, Sunderesakumar P, Ford JM. Defective repair of oxidative dna damage in triple-negative breast cancer confers sensitivity to inhibition of poly(ADP-ribose) polymerase. Cancer Res. 2009; 69:3589-3596.

33. Stilmann M, Hinz M, Arslan SC, Zimmer A, Schreiber V, Scheidereit C. A nuclear poly(ADP-ribose)-dependent signalosome confers DNA damage-induced IkappaB kinase activation. Mol Cell. 2009; 36:365-378.

34. Hinz M, Stilmann M, Arslan SC, Khanna KK, Dittmar G, Scheidereit C. A cytoplasmic ATM-TRAF6-cIAP1 module links nuclear DNA damage signaling to ubiquitin-mediated NF-kappaB activation. Mol Cell. 2010; 40:63-74.

35. Hu MC, Lee DF, Xia W, Golfman LS, Ou-Yang F, Yang JY, Zou Y, Bao S, Hanada N, Saso H, Kobayashi R, Hung MC. IkappaB kinase promotes tumorigenesis through inhibition of forkhead FOXO3a. Cell. 2004; 117:225-237.

36. Tsai WB, Chung YM, Zou Y, Park SH, Xu Z, Nakayama K, Lin $\mathrm{SH}, \mathrm{Hu} \mathrm{MC}$. Inhibition of FOXO3 tumor suppressor function by betaTrCP1 through ubiquitin-mediated degradation in a tumor mouse model. PLoS One. 2010; 5:e11171.

37. Wang S, Wang H, Davis BC, Liang J, Cui R, Chen SJ, Xu ZX. PARP1 inhibitors attenuate AKT phosphorylation via the upregulation of PHLPP1. Biochem Biophys Res Commun. 2011; 412:379-384.

38. Cha EJ, Noh SJ, Kwon KS, Kim CY, Park BH, Park HS, Lee H, Chung MJ, Kang MJ, Lee DG, Moon WS, Jang KY. Expression of DBC1 and SIRT1 is associated with poor prognosis of gastric carcinoma. Clin Cancer Res. 2009; 15:4453-4459.

39. Allred DC, Harvey JM, Berardo M, Clark GM. Prognostic and predictive factors in breast cancer by immunohistochemical analysis. Modern pathology. 1998; 11:155-168.

40. Kim JR, Moon YJ, Kwon KS, Bae JS, Wagle S, Yu TK, Kim KM, Park HS, Lee JH, Moon WS, Lee H, Chung MJ, Jang KY. Expression of SIRT1 and DBC1 Is Associated with Poor Prognosis of Soft Tissue Sarcomas. PLoS One. 2013; 8:e74738. 